\title{
Dilated Intercellular Spaces: A Morphological Feature of Acid Reflux-Damaged Human Esophageal Epithelium
}

\author{
NELIA A. TOBEY,* JOHNNY L. CARSON, ${ }^{\ddagger}$ RADWAN A. ALKIEK,* and ROY C. ORLANDO* \\ *Department of Medicine, Tulane University School of Medicine, and Veterans Administration Medical Center, New Orleans, Louisiana; and \\ ${ }^{\ddagger}$ Department of Pediatrics and the Center for Environmental Medicine and Lung Biology, University of North Carolina School of Medicine, \\ Chapel Hill, North Carolina
}

Background \& Aims: Dilated intercellular spaces are a sign of epithelial damage in acid-perfused rabbit esophagus, a change best identified by transmission electron microscopy. The aim of this study was to determine if this change is also a feature of acid damage to human esophageal epithelium. Methods: Endoscopic esophageal biopsy specimens from patients with $(n=11)$ and without $(n=13)$ recurrent heartburn were examined using transmission electron microscopy. Of 11 patients with heartburn, 6 had erosive esophagitis and 5 had normal-appearing mucosa on endoscopy; 13 controls had no symptoms or signs of esophageal disease. Using a computer, intercellular space diameter was measured from transmission electron microscopy photomicrographs of the specimen from each patient. Results: Intercellular space diameter was significantly greater in specimens from patients with heartburn than those from controls; this was true irrespective of whether the patient had erosive or nonerosive disease. Space diameters of $\geq 2.4 \mu \mathrm{m}$ were present in 8 of 11 patients with heartburn and in no controls. Conclusions: Dilated intercellular spaces are a feature of reflux damage to human esophageal epithelium. As a morphological marker of increased paracellular permeability, its presence in patients without endoscopic abnormalities may help explain their development of heartburn.

$\mathrm{T}$ he acid-perfused rabbit esophagus has been a useful model for investigating the pathophysiology of human gastroesophageal reflux disease (GERD). Rabbit and human esophageal (stratified squamous) epithelia are similar structurally and functionally and respond similarly to acid exposure. ${ }^{1-9}$ For instance, during short-term acid exposure, both rabbit and human esophageal epithelia show an initial increase in esophageal potential difference (PD), which is followed by a progressive decrease until the PD is eliminated. Additionally, when the PD is abolished, both human and rabbit esophageal epithelia have been shown to have macroscopic erosive changes within the tissue. ${ }^{2,4}$ Notably, before the onset of cell necrosis and elimination of PD, another morphological change is identifiable within the acid-perfused rabbit esophagus, i.e., the presence of dilated intercellular spaces within the esophageal epithelium. Because this change, which is poorly visible by light microscopy but readily identifiable by transmission electron microscopy, correlates with an increase in transepithelial mannitol flux, it reflects an increase in (paracellular) permeability across the acid-damaged intercellular junctions of the epithelium. ${ }^{1,10}$ On the basis of these observations and seeking to provide additional correlations between experimental model and human disease, we examined whether dilated intercellular spaces are also a feature of acid damage to human esophageal epithelium using transmission electron microscopy on endoscopic esophageal biopsy specimens from patients with and without recurrent heartburn, heartburn being the hallmark of GERD.

\section{Materials and Methods}

\section{Subjects}

After obtaining written informed consent from patients scheduled to undergo upper endoscopy for clinical reasons, demographic and historical data were obtained from the patient and medical record. This information and subsequent clinical follow-up were used to categorize patients as having active GERD or being suitable non-GERD controls. The diagnosis for active GERD included (1) the presence of recurrent episodes of typical heartburn, (2) an endoscopy that was negative for other non-GERD conditions to explain symptoms, and (3) an appropriate response to medical antireflux therapy, i.e., symptoms and/or lesions improved by using a medication or dosage that increased the degree of inhibition of gastric acid secretion. Control patients had no history of esophageal symptoms such as odynophagia, regurgitation, dysphagia, or heartburn or any history of esophageal disease. Four of the control

\footnotetext{
Abbreviation used in this paper: GERD, gastroesophageal reflux disease.

(C) 1996 by the American Gastroenterological Association 0016-5085/96/\$3.00
} 


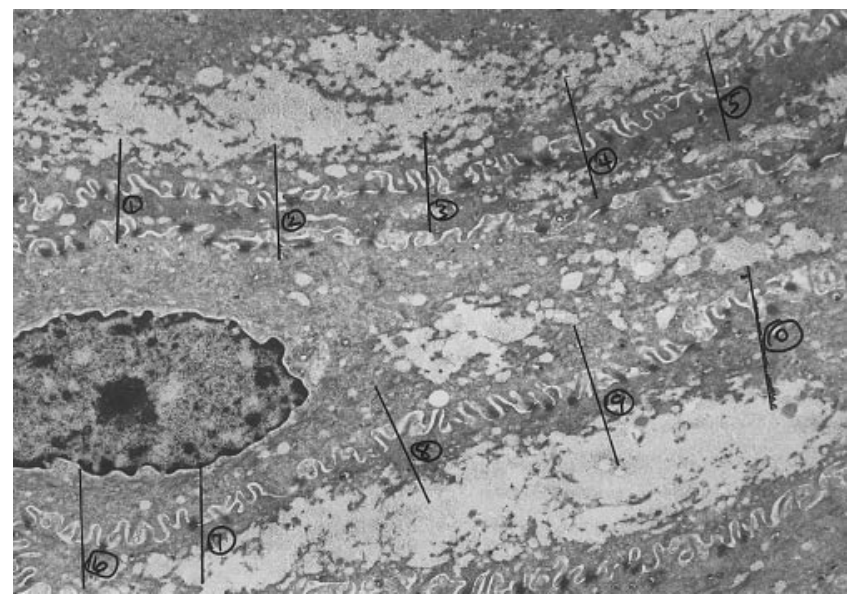

Figure 1. A transmission electron photomicrograph of a human esophageal biopsy specimen showing the method used for measuring intercellular space diameter. Transects perpendicular to opposing cell membranes are randomly drawn across the intercellular spaces from regions in the photomicrograph representative of the fiel as a whole. No transect was closer than $1 \mu \mathrm{m}$ from its neighbor (original magnifi cation $3000 \times)$.

patients were using nonsteroidal anti-inflammatory drugs (NSAID) on a long-term basis.

Upper endoscopy was performed after interview, and subjects with GERD were subdivided into those with erosive

Table 1. Demographic Data From Patients With and Without GERD

\begin{tabular}{|c|c|c|c|c|c|}
\hline & Age $(y r)$ & Sex & Race & Smoking & Alcohol \\
\hline \multicolumn{6}{|c|}{ Controls } \\
\hline 1 & 46 & $M$ & Black & No & No \\
\hline 2 & 61 & M & Black & Yes & Yes \\
\hline 3 & 78 & $M$ & Black & No & No \\
\hline 4 & 65 & $M$ & White & Yes & No \\
\hline 5 & 45 & M & Black & No & No \\
\hline 6 & 70 & $\mathrm{~F}$ & Black & Yes & No \\
\hline 7 & 39 & $\mathrm{~F}$ & White & Yes & No \\
\hline 8 & 50 & $\mathrm{~F}$ & Black & Yes & No \\
\hline 9 & 57 & M & Black & Yes & No \\
\hline 10 & 67 & $\mathrm{M}$ & Black & Yes & No \\
\hline 11 & 51 & M & White & Yes & No \\
\hline 12 & 54 & M & White & No & Yes \\
\hline 13 & 62 & $\mathrm{M}$ & White & Yes & Yes \\
\hline \multicolumn{6}{|c|}{ Patients with GERD } \\
\hline \multicolumn{6}{|c|}{ Erosive disease } \\
\hline 1 & 43 & M & Black & No & No \\
\hline 2 & 40 & $\mathrm{M}$ & White & Yes & No \\
\hline 3 & 75 & M & White & No & No \\
\hline 4 & 57 & M & Hispanic & No & No \\
\hline 5 & 51 & $\mathrm{~F}$ & White & No & No \\
\hline 6 & 49 & $\mathrm{~F}$ & White & Yes & No \\
\hline \multicolumn{6}{|c|}{ Nonerosive disease } \\
\hline 1 & 62 & M & White & No & Yes \\
\hline 2 & 45 & $\mathrm{~F}$ & White & No & No \\
\hline 3 & 40 & M & White & Yes & Yes \\
\hline 4 & 65 & M & Hispanic & No & No \\
\hline 5 & 45 & M & Black & No & No \\
\hline
\end{tabular}

Table 2. Transmission Electron Microscopy Scores in Mean and Maximum Measurement of Degrees of Dilated Intercellular Spaces in Biopsy Specimens From Controls and Patients With Reflu Eosphagitis

\begin{tabular}{lcc}
\hline \multicolumn{1}{c}{ Patients } & $\begin{array}{c}\text { Mean scores } \\
(\mu \mathrm{m})\end{array}$ & $\begin{array}{c}\text { Maximum } \\
\text { scores } \\
(\mu \mathrm{m})\end{array}$ \\
\hline Controls $(\mathrm{n}=13)$ & $0.46 \pm 0.06$ & $1.45 \pm 0.15$ \\
Erosive reflu $(\mathrm{n}=6)$ & $0.80 \pm 0.12^{a}$ & $2.89 \pm 0.26^{a}$ \\
Nonerosive reflu $(\mathrm{n}=5)$ & $1.00 \pm 0.15^{a}$ & $2.78 \pm 0.45^{a}$ \\
\hline
\end{tabular}

NOTE. Values are means \pm SEM.

${ }^{a} P<0.05$ compared with controls.

esophagitis, documented by mucosal breaks on endoscopy, and those with symptomatic reflux but normal-appearing mucosa on endoscopy. Controls by definition had to have completely normal-appearing mucosa within the esophagus on endoscopy. From each patient, biopsy specimens were obtained within the lower $5 \mathrm{~cm}$ of esophagus from areas of macroscopically intact (noneroded) esophageal mucosa. This project was approved by the human research committees at all participating hospitals.

Specimens from each patient were immediately fixed in 0.1 $\mathrm{mol} / \mathrm{L}$ phosphate buffer, $\mathrm{pH} 7.2$, containing $2 \%$ glutaraldehyde plus $2 \%$ paraformaldehyde and coded so that the category of the patient (GERD or control) was unknown to the morphologist (J.L.C.). One specimen from each patient was selected for processing by transmission electron microscopy. The specimen was rinsed in buffer, postfixed in $1 \%$ buffered osmium tetroxide, and dehydrated through a graded alcohol series. It was then infiltrated through propylene oxide and embedded in an epoxy resin. Blocks were trimmed, and ultrathin sections on copper grids were poststained with uranyl acetate and lead citrate. Each specimen was examined and photographed in a Zeiss EM900 transmission electron microscope at an accelerating voltage of $50 \mathrm{kV}$ (Carl Zeiss, Thornwood, NY). Photographs of 10 representative microscopic fields, each with a negative containing an internal scale marker, were enlarged to an $8 \times 10$ print, and these were used for a computer-generated morphometric analysis of intercellular space diameter for each patient.

\section{Computer-Assisted Morphometry}

On each of the 10 photomicrographs of a given patient's biopsy specimen, a fine-tipped marker was used to draw 10 transects across randomly selected areas of intercellular space. Each transect across the intercellular space was drawn perpendicular to the membranes of adjacent cells, and no 2 transects were drawn closer than $1 \mu \mathrm{m}$ apart (Figure 1). This process resulted in 100 transects being drawn and available for measurement of intercellular space diameter in the esophageal biopsy of each patient. The marked photographs with internal scale markers were digitized, the images were stored on a disk, and the diameter of each of the transected intercellular spaces 

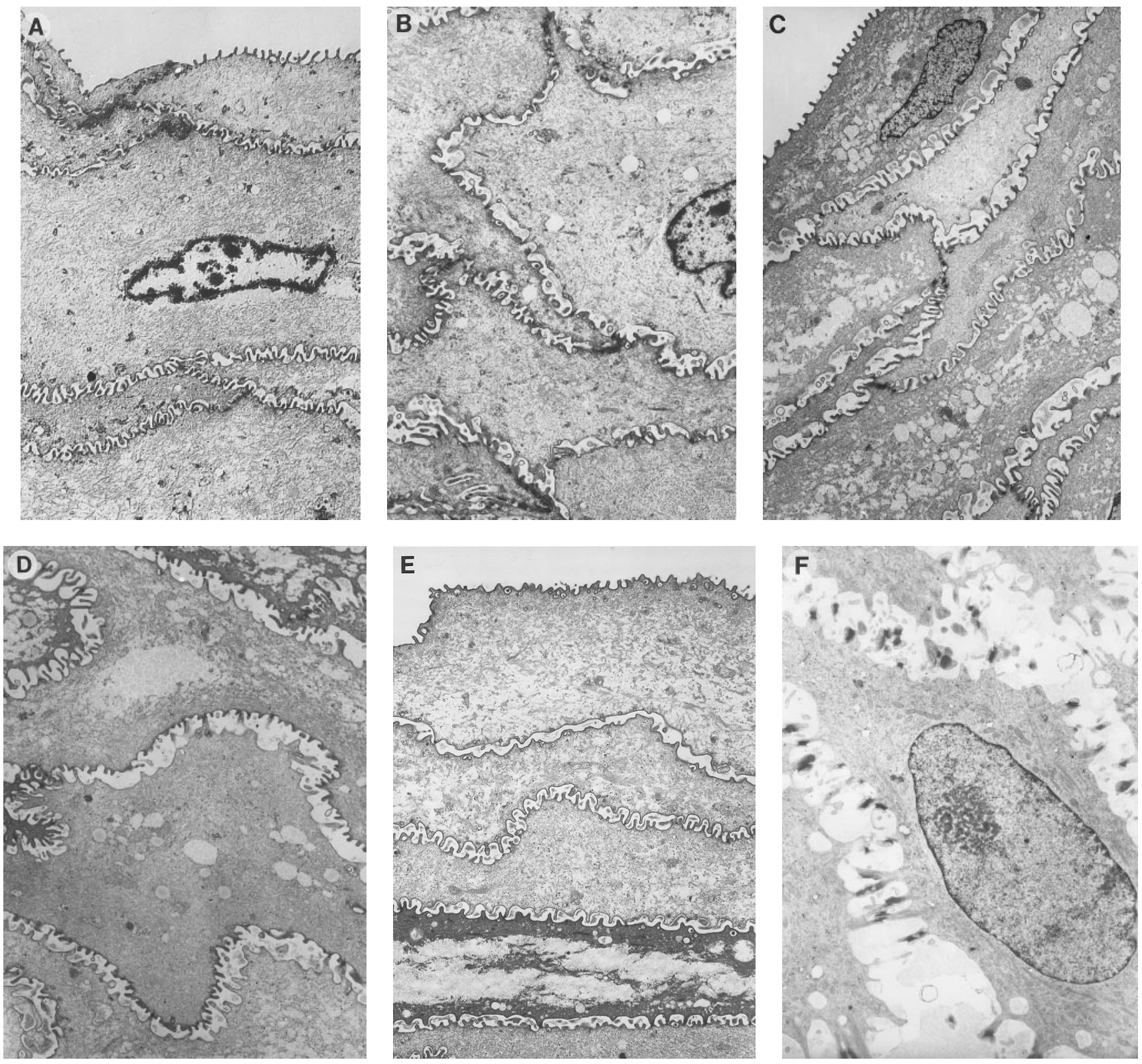

Figure 2. A pair of transmission electron photomicrographs of esophageal biopsy specimens from 3 patients. Each photo pair includes a photo from an area of epithelium near the luminal surface $(A, C$, and $E$ ) and a second area deep within the epithelium $(B, D$, and $F)$. ( $A$ and $B)$ Control patient with no symptoms or signs of reflu or other esophageal disease. ( $C$ and $D$ ) Patient with symptomatic reflu (heartburn) but a grossly normal esophagus on endoscopy. ( $E$ and $F$ ) Patient with heartburn and erosive esophagitis on endoscopy. The biopsy specimen from the patient with erosive esophagitis, similar to the specimens from the other patients, was taken from an area of endoscopically normal-appearing esophageal mucosa (original magnificatio $3000 \times$ ).

was determined using Image-Pro Plus software (Media Cybernetics, Silver Spring, MD). The mean value of intercellular space diameter was computed for each patient by averaging the 100 transects in the 10 photographs of a given patient's specimen.

\section{Statistics}

Statistical significance was determined using Student's $t$ test for unpaired samples. Data are reported as the mean \pm SEM.

\section{Results}

Esophageal biopsy specimens were obtained from 11 patients with GERD and 13 controls. Six of 11 patients with GERD had erosive esophagitis (grades I-IV according to classification of Savary-Miller, in which grade $\mathrm{I}$ is single erosions or erosions on a single fold, grade II is multiple erosions on more than one fold, grade III is circumferential erosions, and grade IV is erosions 

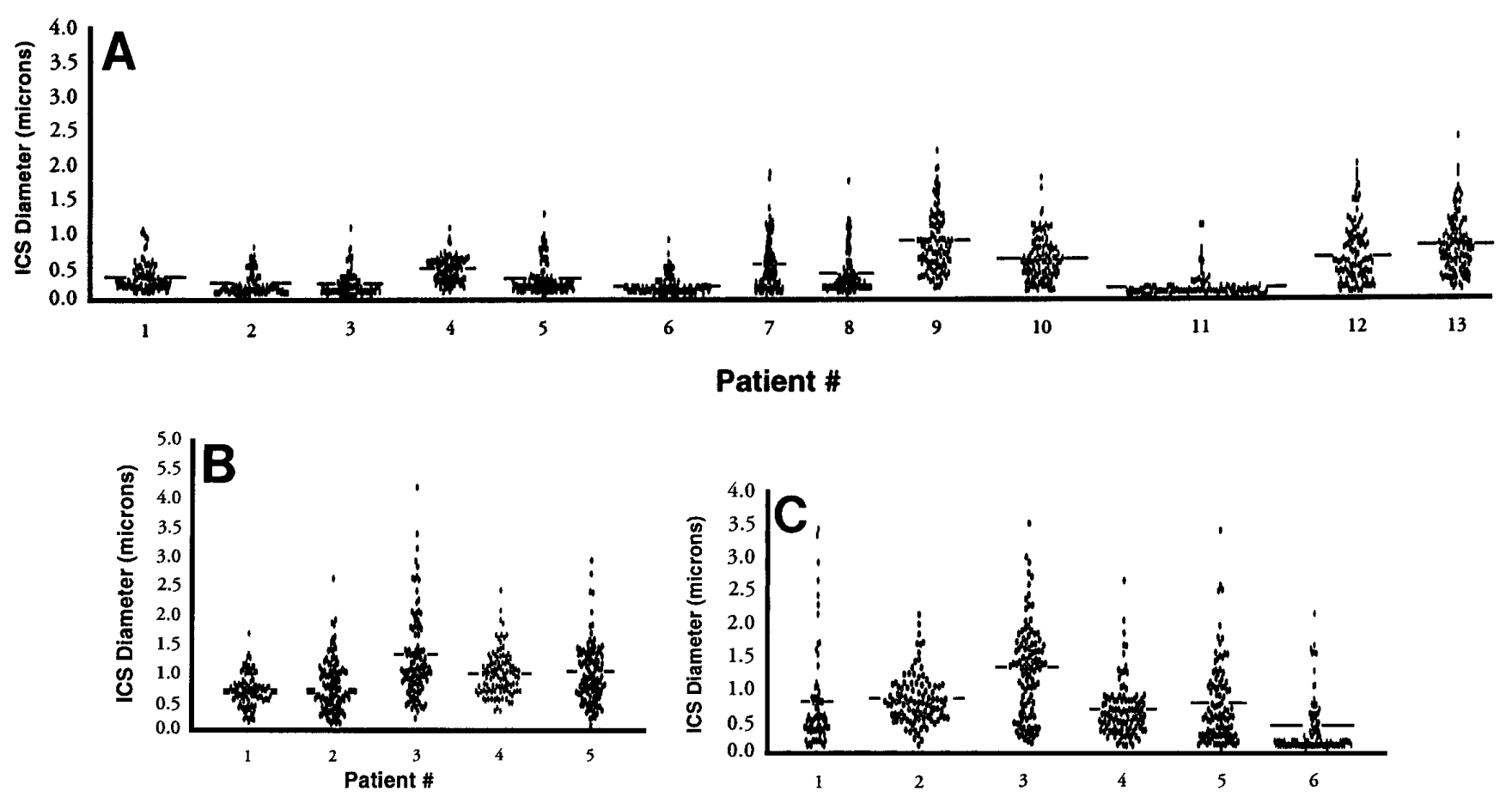

Figure 3. A scattergram showing the distribution of the 100 measured values for intercellular space (ICS) diameter for each $(A)$ control patient $(n=13),(B)$ patient with symptomatic reflu (heartburn) and endoscopically normal-appearing mucosa $(n=5)$, and $(C)$ patient with heartburn and erosive esophagitis $(n=6)$.

plus stricture formation), and 5 had symptomatic reflux with completely normal-appearing esophageal mucosa on endoscopy. As evidence in support of the diagnosis of GERD, all 6 patients with erosive esophagitis, including 2 patients who had mild strictures not requiring dilatation, improved on omeprazole therapy at doses of $20-$ $40 \mathrm{mg} /$ day. All 5 patients with nonerosive disease had symptoms effectively controlled with ranitidine at doses ranging from 150 to $300 \mathrm{mg}$ twice daily. Table 1 lists the demographic data for each group. The control population had slightly more blacks than whites (8 vs. 2) than the GERD population and more current cigarette smokers (9 vs. 3). There was no difference in either age, sex, or regular alcohol use among the groups.

Based on computer-generated measurements of the transects drawn by a microscopist blinded to patient category, the mean and maximal esophageal epithelial intercellular space diameters calculated for the patients with GERD were approximately two times greater than those for controls (Table 2). Although the number of patients with GERD and symptomatic (nonerosive) reflux was small, intercellular space mean or maximal diameters were similar irrespective of whether the patients had erosive or nonerosive (symptomatic reflux) disease. (Biopsy specimens from all groups were obtained from areas of endoscopically intact esophageal mucosa.) Also, athough there were significantly more blacks than whites in the control group ( 8 of 13 ) than in the GERD population (2 of 11), the presence or absence of dilated intercellular spaces was not distinguishable by race but correlated directly in each subgroup with the presence or absence of GERD. The control group included 4 NSAID users whose values for intercellular space diameter did not differ significantly from those of the other 9 non-NSAID user controls $(0.40 \pm 0.13$ and $0.48 \pm 0.07$, respectively; $P>0.05)$.

The above findings are readily appreciated by viewing a pair of transmission electron photomicrographs from 1 patient in each group (Figure 2) and by viewing a plot of the 100 measurements of intercellular space diameter for each patient with erosive and nonerosive GERD and controls (Figure 3). On the basis of the plots in Figure $3 A-C$, it can be seen that all 11 patients with GERD had at least one or more values for intercellular space diameter of $\geq 1.5 \mu \mathrm{m}$; similar values were observed in 6 of 13 controls. Further, 8 of 11 patients with GERD had intercellular space diameters of $\geq 2.4 \mu \mathrm{m}$, whereas none of the controls had values within this range. Based on the present study, the value of $>2.4 \mu \mathrm{m}$ for intercellular space diameter was calculated to have $100 \%$ specificity and $73 \%$ sensitivity as a discriminator between GERD and non-GERD patient populations; however, a 
much larger database will be needed before it can be determined if these values have clinical use. Differences in intercellular space diameter between GERD and nonGERD patient populations could not be ascribed to differences in race because there was no difference in intercellular space diameter between black $(0.41 \pm 0.08$; $\mathrm{n}$ $=8)$ and white $(0.54 \pm 0.10 ; \mathrm{n}=5 ; P>0.05)$ controls or black $(0.89 ; \mathrm{n}=2)$ and white $(0.91 \pm 0.15 ; \mathrm{n}=7)$ patients with GERD. Also, intercellular space diameters were different between both white controls $(0.54 \pm 0.10$; $\mathrm{n}=5)$ and white patients with GERD $(0.91 \pm 0.15 ; \mathrm{n}$ $=7 ; P<0.05)$ and between black controls $(0.41 \pm$ $0.08 ; \mathrm{n}=8)$ and black patients with GERD $(0.89 ; \mathrm{n}=$ 2).

\section{Discussion}

The motivation for this study was the observation that dilated intercellular spaces were a morphological feature of acid damage in esophageal epithelium of experimental animals. ${ }^{1,10}$ In this study, we document that similar pathology is detectable within the acid-exposed human esophagus, represented by a population of patients with GERD. Transmission electron microscopy on endoscopically obtained esophageal biopsy specimens showed that patients with GERD were found to have significantly greater intercellular space diameters than controls, i.e., patients undergoing endoscopy for clinical reasons but with neither symptoms nor signs of esophageal disease. An intercellular space diameter of $\geq 2.4 \mu \mathrm{m}$ was present in 8 of 11 patients with GERD (73\%) and in none of the 13 controls. These observations support the presence of dilated intercellular spaces within the esophageal epithelium as another pathological feature of GERD. (Although no quantitative comparisons have been previously performed, the presence of dilated intercellular spaces within human esophageal epithelium has been shown previously in patients with GERD. ${ }^{10,11}$ ) Further, dilated intercellular spaces were not only observed within the normal-appearing mucosa of patients with erosive esophagitis but were present in the normal-appearing mucosa of patients with symptomatic (nonerosive) reflux disease. Because this feature in the acid-exposed rabbit esophagus correlates with an increase in (paracellular) permeability across the acid-damaged esophageal epithelium, its presence may explain why patients with endoscopically normal mucosa readily develop heartburn on exposure to an acidic refluxate. Support for this is found in studies showing that the sensory neurons within the esophagus terminate within the intercellular space only a few cell layers from the lumen. ${ }^{12}$
In addition, the present study has importance in establishing another (morphological) parallel between the experimental (rabbit) model of acid-induced esophageal damage and human reflux disease. The presence of dilated intercellular spaces in both acid-damaged rabbit esophagus and human acid reflux disease occurs in both conditions before the onset of gross morphological damage, suggesting that it may be an earlier lesion (than cell necrosis) in the acid-damage sequence. This morphological feature of acid damage also supports the concept that acid damages the intercellular junctional structures and increases paracellular permeability before the onset of tissue necrosis.

In summary, the present study verifies in humans a hypothesis generated from an experimental animal model: dilated intercellular spaces are a sign of acid damage in esophageal epithelium. The presence of this lesion in GERD, both with and without macroscopic evidence of disease, offers both a mechanism for the ready precipitation of symptoms during acid reflux (through the ease of acid access to sensory neurons within the leaky epithelium) and an opportunity for its further assessment as a more sensitive marker of GERD.

\section{References}

1. Carney CN, Orlando RC, Powell DW, Dotson MM. Morphologic alterations in early acid-induced epithelial injury of the rabbit esophagus. Lab Invest 1981; 45:198 -208.

2. Orlando RC, Bryson JC, Powell DW. Mechanisms of $\mathrm{H}+$-induced injury in rabbit esophageal epithelium. Am J Physiol 1984; 246 : G718-G724.

3. Orlando RC, Powell DW, Carney CN. Pathophysiology of acute acid injury in rabbit esophageal epithelium. J Clin Invest 1981; 68:286-293.

4. Orlando RC, Powell DW. Studies of esophageal epithelial electrolyte transport and potential difference in man. In: Allen A, Flemstrom G, Garner A, Silen W, Turnberg LA, eds. Mechanisms of mucosal protection in the upper gastrointestinal tract. New York: Raven, 1984:75 -79.

5. Al-Yassin TM, Toner PG. Fine structure of squamous epithelium and submucosal glands of human esophagus. J Anat 1977; 123: $705-721$.

6. Hopwood D, Logan KR, Bouchier IAD. The electron microscopy of normal human esophageal epithelium. Virchows Arch B Cell Pathol Mol Pathol 1978; 26:345 -358.

7. Rhodin JAG. Histology: a text and atlas. New York: Oxford University, 1975:536.

8. Turner KS, Powell DW, Carney CN, Orlando RC, Bozymski E. Transmural electrical potential difference in the mammalian esophagus in vivo. Gastroenterology 1978; 75:286 -291.

9. Orlando RC, Lacy ER, Tobey NA, Cowart K. Barriers to paracellular permeability in rabbit esophageal epithelium. Gastroenterology 1992; 102:910 -923.

10. Hopwood D, Milne G, Logan KR. Electron microscopic changes in human oesophageal epithelium in oesophagitis. J Pathol 1979; 129:161 -167. 
11. Pope CE II. Gastroesophageal reflu disease (reflu esophagitis). In: Sleisenger MH, Fordtran JS, eds. Gastrointestinal disease: pathophysiology, diagnosis, management. Volume 1. 2nd ed. Philadelphia: Saunders, 1978:541-568.

12. Rodrigo J, Hernandez DJ, Vidal MA, Pedrosa JA. Vegetative innervation of the esophagus III. Intraepithelial endings. Acta Anat 1975; 92:242 -258.
Received February 1, 1996. Accepted July 15, 1996.

Address requests for reprints to: Roy C. Orlando, M.D., Tulane University Medical Center, 1430 Tulane Avenue, New Orleans, Louisiana 70112. Fax: (504) 587-2188.

Supported in part by National Institutes of Health grant R01DK36013 and by Glaxo Inc. (Research Triangle Park, NC). 